\title{
BMJ Open Effects of cancer treatment on household impoverishment: a multicentre cross-sectional study in China
}

\author{
Wenqi Fu (D) , ' Jufang Shi, ${ }^{2}$ Xin Zhang, ${ }^{1}$ Chengcheng Liu, ${ }^{2}$ Chengyao Sun, ${ }^{1}$ \\ Yupeng Du, ${ }^{1}$ Hong Wang, ${ }^{1}$ Chaojie Liu (1) ${ }^{3}$ Li Lan, ${ }^{4}$ Min Zhao, ${ }^{5}$ Li Yang, ${ }^{6}$ \\ Burenbatu Bao, ${ }^{7}$ Sumei Cao, ${ }^{8}$ Yongzhen Zhang, ${ }^{9}$ DeBin Wang, ${ }^{10} \mathrm{Ni} \mathrm{Li},{ }^{2}$ \\ Wanqing Chen, ${ }^{2}$ Min Dai, ${ }^{2}$ Guoxiang Liu (D) , ${ }^{1} \mathrm{Jie} \mathrm{He}^{2}$
}

To cite: Fu W, Shi J, Zhang X, et al. Effects of cancer treatment on household impoverishment: a multicentre cross-sectional study in China. BMJ Open 2021;11:e044322. doi:10.1136/ bmjopen-2020-044322

- Prepublication history and additional supplemental material for this paper are available online. To view these files, please visit the journal online (http://dx.doi.org/10.1136/ bmjopen-2020-044322).

WF and JS contributed equally.

Received 03 September 2020 Accepted 17 May 2021

Check for updates

(C) Author(s) (or their employer(s)) 2021. Re-use permitted under CC BY-NC. No commercial re-use. See rights and permissions. Published by BMJ.

For numbered affiliations see end of article.

Correspondence to Professor Guoxiang Liu; Igx6301@163.com and Dr Wanqing Chen; chenwq@cicams.ac.cn

\section{ABSTRACT}

Objectives To determine the incidence and intensity of household impoverishment induced by cancer treatment in China.

Design Average income and daily consumption per capita of the households and out-of-pocket payments for cancer care were estimated. Household impoverishment was determined by comparing per capita daily consumption against the Chinese poverty line (CPL, US\$1.2) and the World Bank poverty line (WBPL, US\$1.9) for 2015. Both pre-treatment and post-treatment consumptions were calculated assuming that the households would divert daily consumption money to pay for cancer treatment.

Participants Cancer patients diagnosed initially from 1 January 2015 to 31 December 2016 who had received cancer treatment subsequently. Those with multiple cancer diagnoses were excluded.

Data sources A household questionnaire survey was conducted on 2534 cancer patients selected from nine hospitals in seven provinces through two-stage cluster/ convenience sampling.

Findings $5.89 \%$ (CPL) to $12.94 \%$ (WBPL) households were impoverished after paying for cancer treatment. The adjusted OR (AOR) of post-treatment impoverishment was higher for older patients $(A O R=2.666-4.187$ for $\geq 50$ years vs $<50$ years, $p<0.001$ ), those resided in central region $(A O R=2.619$ vs eastern, $p<0.01)$ and those with lower income (AOR=0.024-0.187 in higher income households vs the lowest $20 \%, p<0.001$ ). The patients without coverage from social health insurance had higher $\mathrm{OR}(\mathrm{AOR}=1.880, \mathrm{p}=0.040)$ of experiencing post-treatment household impoverishment than those enrolled with the insurance for urban employees. Cancer treatment is associated with an increase of $5.79 \%$ (CPL) and $12.45 \%$ (WBPL) in incidence of household impoverishment. The median annual consumption gap per capita underneath the poverty line accumulated by the impoverished households reached US\$128 (CPL) or US\$212 (WBPL). US\$31 170395 (CPL) or US\$115238459 (WBPL) were needed to avoid household impoverishment induced by cancer treatment in China.

Conclusions The financial burden of cancer treatment imposes a significant risk of household impoverishment despite wide coverage of social health insurance in China.
Strengths and limitations of this study

- This is one of the few studies involving a large sample of cancer patients in China.

- Household impoverishment induced by cancer treatment was estimated, including its socioeconomic inequalities.

- National funds required for alleviating household impoverishment induced by cancer treatment were estimated based on new cases of cancer diagnosis.

- Patients with multiple cancer diagnoses were excluded from the study.

Data were collected through a questionnaire survey, which are subject to recall bias.

\section{INTRODUCTION}

Cancer causes enormous physical and mental harm on patients and their families. ${ }^{1}$ In 2012 , 14.1 million new cases of cancer were reported in the world and 8.2 million cancer patients died. These figures surged to 18.1 million and 9.6 million, respectively, in $2018 .^{23} \mathrm{~A}$ further $75 \%$ increase in new cases of cancer over the next two decades is anticipated. ${ }^{4}$ China bears the highest burden of cancer, ranking on top of the world not only in absolute numbers and deaths but also in proportion to the population size. ${ }^{4}$ It was estimated that 4.3 million new cancer cases were diagnosed and 2.8 million died from cancer in China in $2015 .^{5}$ Cancer has become the leading cause of death in China. The rising trend of cancer shows no sign of containment. ${ }^{6}$

The costs of cancer treatment put a great financial stress on cancer patients and their families. According to the Medical Panel Expenditure Survey, the households with a cancer survivor in the USA were paid on average US $\$ 2304$ out of pocket (OOP) every year over the period from 2008 to $2016 .^{7}$ The annual OOP spending on metastatic breast cancer treatment in the USA during 
2004-2011 reached US\$6642. ${ }^{8}$ A multicentre crosssectional survey in China over the period from 2012 to 2014 showed that the OOP spending of cancer treatment in the first year averaged at US $\$ 4947$, which equalled to $57.5 \%$ of the average annual household income. About $77.6 \%$ of the households with a cancer patient experienced unmanageable financial difficulties. ${ }^{9}$

The high cost of cancer treatment has imposed disproportional burdens on the households living with low income. They are more prone to falling into impoverishment as a result of OOP payments for cancer treatment. This has prompted the WHO to call for increasing policy attention addressing the inequality issue through a systems approach. ${ }^{10-12}$ A study in Heilongjiang, a province ranked in the middle range of economic development in China, showed that as many as $86 \%$ of households with a cancer patient could become impoverished as a result of cancer treatment. ${ }^{13}$

Health insurance has been widely accepted as an effective strategy to prevent household impoverishment induced by cancer treatment. ${ }^{14}$ Although extensive studies have been conducted on the relationship between cancer and poverty, ${ }^{15-18}$ there is paucity in the literature documenting the situation in low-income and middleincome countries. ${ }^{11}$ Most low-income and middle-income countries cannot afford the same level of insurance entitlements as their high-income counterparts. Internationally, little is known about inequality of household impoverishment resulting from cancer treatment and the role of health insurance in alleviating cancer-induced impoverishment. ${ }^{19}$

This study aimed to determine the incidence and intensity of household impoverishment induced by cancer treatment in China. By 2015, more than $95 \%$ of Chinese citizens had been covered by social health insurance. ${ }^{20}$ However, there have been significant disparities in insurance entitlements across regions, between urban and rural, and across different insurance programmes. ${ }^{21}$ There are three social health insurance programmes subsidised by the government: Basic Medical Insurance for Urban Employees (BMIUE), Basic Medical Insurance for Urban Residents (BMIUR), and the New Cooperative Medical Scheme (NCMS). The BMIUE was initiated in 1998 with premium contributions from both employers and employees, covering urban employees and retirees in the formal sector, including those who previously enjoyed free medical care offered by public agencies and stateowned enterprises. Funding resources for the NCMS (initiated in 2003) and BMIUR (initiated in 2007) come from both individual voluntary contributions and local governmental subsides. The former covers rural residents, while the latter covers the urban residents who are not eligible for the BMIUE, such as those self-employed, unemployed, children and students. All these three programmes are managed at the municipal or county level with varied funding pools and benefit policies. The BMIUE enrollees enjoy a relatively higher level of entitlements compared with the other two. Recently, the NCMS and BMIUR started to merge in some regions. ${ }^{202223}$ There is a shortage of research into the role of these insurance programmes in preventing poverty induced by medical care services. The State Council of China made it clear in 2016 that disease-associated poverty would be given priority in the governmental poverty alleviating campaign. ${ }^{24}$

\section{METHODS}

\section{Study design and sites}

A multicentre cross-sectional survey was conducted from January 2018 to June 2019 as part of the Cancer Screening Programme in Urban China. ${ }^{25}$ Geographic regions/provinces were grouped into eastern, central and western in line with the classification of economic development zones by the National Bureau of Statistics. Nine tertiary hospitals were purposively selected from these zones considering cancer patient volumes and completeness of medical records, including Guangdong Cancer Hospital (eastern), Anhui Cancer Hospital, Heilongjiang Cancer Hospital, Shanxi Cancer Hospital (central), Guangxi Cancer Hospital, Yunnan Cancer Hospital, the Regional Cancer Hospital and two city hospitals in Inner Mongolia (western).

\section{Study participants}

Cancer patients diagnosed initially over the period from 1 January 2015 to 31 December 2016 were eligible for this study. They had to receive cancer treatment subsequently. Eligible participants were those who had one primary cancer (including metastatic cancer). Those with two or more primary cancer diagnoses were excluded. The eligibility of study participants was assessed through the hospital records. Lung, breast, colorectum, oesophageal, liver and stomach cancers accounted for $70 \%$ of the total sample. About $27.50 \%$ were diagnosed with a cancer in stage III or stage IV.

Previous study showed that about $20 \%$ households with cancer patients might live in poverty. A sample size of 1600 would allow an estimation of the impoverishment rate with $2 \%$ precision as $\alpha$ being set at $0.05 .{ }^{26}$ Given the rapid development of social health insurance in recent years, cancer-induced impoverishment may have dropped significantly. We increased the sample size to 2500 , with a minimal of 360 patients being contacted in each participating province. In each province, 720 medical records of cancer patients were randomly extracted for the follow-up survey.

\section{Outcome indicators}

Impoverished households were identified by assessing household consumption against the poverty line. ${ }^{27}$ This included regular and repeated expenses to satisfy the essential needs of household members, which only counted the expenses paid OOP, not including those subsidised by the government and insurance. A daily household consumption below US $\$ 1.2$ per capita per day (US\$438 per year) in the 2015 value was deemed 
impoverishment according to the State Council of China. Globally, poverty line was set at US $\$ 1.90$ per capita per day (US\$694 per year) in the 2015 value by the World Bank. ${ }^{28}$

The primary outcome indicators included (1) incidence of household impoverishment as a percentage of households living under the poverty line; and (2) intensity of household impoverishment reflected by the distance of household consumption per capita from the poverty line, which was calculated as the monetary value difference between the poverty line and per capita household consumption after paying for cancer treatment. ${ }^{27}$

The marginal contribution of cancer treatment to household impoverishment was calculated as the difference in incidence of household impoverishment precancer and post-cancer treatment. The expenditure associated with cancer diagnosis and treatment was counted as pre-treatment consumption, which was subsequently deprived from post-treatment consumption. The national scale of impoverishment resulting from cancer treatment was estimated based on the number of new cancer cases reported in 2015 across the three regions in China. A weighting system was applied based on the number of new cancer cases in the estimation of national incidence of household impoverishment: 0.48 for eastern, 0.28 for central and 0.24 for western.

\section{Data collection}

Eligible study participants were identified from the hospital records and then approached for a questionnaire survey. The questionnaire was administered through face-to-face interviews over the period from March 2018 to December 2018. The survey was coordinated by the National Cancer Centre. The interviewers were trained prior to deployment and required to check completeness of the questionnaire before concluding each interview.

In each household, either the patient or her/his primary family caregiver was invited to respond to the questionnaire. Participation was voluntary. Written informed consent was obtained prior to each interview. Of the returned questionnaires, 53\% were completed by the patients, compared with $47 \%$ by their family caregivers (online supplemental table S1). The respondents were asked to estimate OOP payments for cancer treatment over a 1-year period ( 2 months before and 10 months after diagnosis of the cancer). These included OOP payments for hospital diagnosis and treatment and medicines (both prescribed and non-prescribed) purchased from pharmacy retail outlets.

The household income and consumption data covered both 2015 and 2016. Average income and consumption across the 2 years were calculated to match the cancer treatment cost data due to difficulties to articulate a clear cut-off point for the income and consumption data.

The questionnaire items measuring household income and consumption (online supplementary table S2) were derived from the National Health Services Survey and the Statistical Bulletin on National Economic and Social
Development in China. Income included salary, return on capital investments, dividends and interests, governmental subsidies and gifts. Household consumptions included foods, clothing, daily necessities, transportation, communication, housing (mortgage/rents and utilities), education, medical care, insurance, and cultural and entertainment activities. Capital investments and repairments and other profit generating investment activities were excluded.

In this study, we only estimated direct OOP payments for cancer treatment (online supplemental table S1). Indirect costs associated with transportation and travel, meals, and informal caregivers were excluded. All of the three social health insurance programmes had very detailed descriptions of covered items. The insured patients needed to pay for all of the uncovered items (including some drugs for cancer therapy). On top of that, there were deductible (insurance compensations would start only when medical expenditure exceeded a defined minimal level), copayments (share of fee between insurance and the insured), and ceiling requirements (insurance would stop compensations once the expenses reached a defined maximal level).

Data were double-entered into EpiData V.3.1 to ensure accuracy.

\section{Data analysis}

Data about cancer treatment expenditure, household income and consumption were converted to the 2015 value of US\$ (1 US $\$=6.2284$ Chinese Yuan) for the purpose of assessing impoverishment against the 2015 poverty line set up by the State Council of China and the World Bank.

Pen's parade graphs were produced to visualise the effect of OOP payments for cancer treatment on household impoverishment. Per-capita household consumptions were plotted along the $y$-axis against the cumulative percentage of households ranked by per capita household consumptions along the x-axis for pre-treatment and post-treatment, respectively. The graphs give a clear indication on the proportion of households living below the poverty line. The area covered by the parade of those below the poverty line indicates the gap in household consumption that needs to fill up to alleviate poverty. ${ }^{27}$

Inequality in household impoverishment induced by cancer treatment was assessed by comparing the pretreatment-post-treatment differences in incidence of household impoverishment in patients with different household incomes and insurance coverage. The patients were divided into quintile according to per capita household income. ${ }^{29}$

Logistic regression models were established to determine the socioeconomic characteristics of cancer patients associated with post-treatment household impoverishment after adjustment for variations in other variables. An enter approach was adopted in the modelling involving the independent variables with a significant association with post-treatment impoverishment in the univariate 
analyses. Collinearity of the independent variables was tested through correlation analyses and the variance inflation factor (online supplemental tables S3 and S4).

Sensitivity tests were performed by comparing the results between the self-respondents and those from the caregivers.

The statistical analyses were performed using Excel 2010 and IBM SPSS V.22. A p value less than 0.05 was considered statistically significant.

\section{Patients and public involvement statement}

Patients or the public were not involved in the design, or conduct, or reporting, or dissemination plans of our research.

\section{RESULTS}

A total of 4874 cancer patient records were extracted from the participating hospitals and 2565 patients were followed up. This resulted in a final sample size of 2534 for data analyses after excluding incomplete questionnaires.

\section{Characteristics of respondents}

The respondents had an average age of 59 years $(\mathrm{SD}=13)$. About $58 \%$ were female. More than $85 \%$ came from the central (developing) and western (underdeveloped) regions. Less than half completed higher than senior high school education. The majority $(88 \%)$ were married; $70 \%$ lived in an urban community and nearly $50 \%$ were covered by BMIUE. About $30 \%$ were engaged in farming. Lung, breast, colorectum, oesophagus, liver and stomach cancers accounted for $70 \%$ of the total cases (table 1).

\section{Incidence of household impoverishment}

In 2015, China reported 3.95 million new cases of cancer: $40 \%$ from rural. Almost half $(48 \%)$ were reported from the eastern zone (online supplementary table S5).

Prior to cancer treatment, $0.10 \%$ and $0.49 \%$ of the households were impoverished according to the Chinese poverty line (CPL) and the global poverty line, respectively. These figures increased to $5.89 \%$ and $12.94 \%$, respectively, after cancer treatment (table 2, figures 1 and 2).

There was an increase of $5.79 \%$ households living in poverty after cancer treatment according to the CPL. This amounted to 220978 households. These figures increased to $12.45 \%$ and 475333 households using the global poverty line. The chance of falling into poverty after cancer treatment in rural residents was almost three times of those living in an urban community. Those living in the less developed western and central regions were also two or three times more likely to experience household impoverishment resulting from cancer treatment compared with their more developed eastern counterparts. Rural households and those living in the central region had the biggest increase in impoverishment resulting from cancer treatment (table 2).
Older patients were more likely to experience posttreatment household impoverishment than their younger counterparts $(p<0.001)$. Peasants and those who received lower levels of education were more likely to be impoverished than others $(p<0.001)$. Higher incidence of posttreatment household impoverishment was found in the respondents with lung, oesophagus and stomach cancers $(p<0.001)$. There existed significant regional and wealthrelated disparities in incidence of post-treatment household impoverishment. The patients who lived in the less developed central and western regions had a rural residency, and who enrolled with the less generous NCMS had a higher incidence of post-treatment household impoverishment than others $(\mathrm{p}<0.001)$. The lowest quintile of income group had $25.98 \%$ incidence of post-treatment household impoverishment, compared with less than $6 \%$ incidence of the other income groups $(\mathrm{p}<0.001)$. No significant differences were found in incidence of posttreatment household impoverishment across gender, marital status and stages of cancer (table 1).

\section{Socioeconomic inequalities in household impoverishment}

The households with the lowest quintile of income were hardest hit by cancer treatment, with $25.39 \%$ households falling into poverty under the Chinese line as a result of cancer treatment compared with $44.49 \%$ under the global poverty line. These figures were at least four times higher than those of the households with higher income. Inequalities in financial protection functions of the social health insurance programmes were evident. The rural patients enrolled with NCMS had similar levels of incidence of household impoverishment as compared with those without a coverage of any of the social health insurance programmes, much higher than those covered by the two urban insurance programmes, BMIUE and BMIUR (table 3).

The logistic regression model showed that the incidence of post-treatment household impoverishment was associated with age, site of cancer, region, social health insurance and household income after adjustment for variations in other variables. The incidence of post-treatment household impoverishment increased with age. The patients with breast cancer had lower $\mathrm{OR}(\mathrm{AOR}=0.538$, $\mathrm{p}=0.014$ ) of experiencing post-treatment household impoverishment than those with lung cancer. The OR of the households in the central region $(\mathrm{AOR}=2.619$, $\mathrm{p}=0.006$ ) experiencing post-treatment household impoverishment more than doubled that in the most developed eastern region. Significant lower OR $(\mathrm{p}<0.001)$ of posttreatment household impoverishment were found in the households with higher income compared with those in the lowest quintile of income group. The patients without a coverage of any of the three social health insurance had higher OR (AOR=1.880, $\mathrm{p}=0.040$ ) of experiencing post-treatment household impoverishment than those enrolled with BMIUE (table 4). Further analyses indicated that the regional effect had limited interactions, if any, with the effect of urban-rural residency. The correlation 
Table 1 Characteristics of study participants and post-treatment impoverishment

\begin{tabular}{|c|c|c|c|c|c|c|c|c|}
\hline \multirow[b]{2}{*}{ Characteristics } & \multirow{2}{*}{\multicolumn{2}{|c|}{$\begin{array}{l}\text { Sample size } \\
\text { N (\%) }\end{array}$}} & \multicolumn{3}{|c|}{$\begin{array}{l}\text { Household consumption below } \\
\text { CPL US } \$ 1.2\end{array}$} & \multicolumn{3}{|c|}{$\begin{array}{l}\text { Household consumption below } \\
\text { global poverty line US } \$ 1.9\end{array}$} \\
\hline & & & Number & $\%$ & P value* & Number & $\%$ & P value* \\
\hline Gender & & & & & 0.170 & & & 0.072 \\
\hline Male & 1076 & $(42.46)$ & 91 & 8.46 & & 191 & 17.75 & \\
\hline Female & 1458 & (57.54) & 102 & 7.00 & & 220 & 15.09 & \\
\hline Age (years) & & & & & $<0.001$ & & & $<0.001$ \\
\hline$\leq 49$ & 665 & (26.24) & 24 & 3.61 & & 56 & 8.42 & \\
\hline $50-69$ & 1403 & (55.37) & 122 & 8.70 & & 268 & 19.10 & \\
\hline$\geq 70$ & 466 & (18.39) & 47 & 10.09 & & 87 & 18.67 & \\
\hline Education & & & & & $<0.001$ & & & $<0.001$ \\
\hline$\leq$ Juniorhigh school & 1392 & (54.93) & 149 & 10.70 & & 301 & 21.62 & \\
\hline Senior high school & 609 & (24.03) & 32 & 5.25 & & 75 & 12.32 & \\
\hline$\geq$ University & 533 & (21.04) & 12 & 2.25 & & 35 & 6.57 & \\
\hline Occupation & & & & & $<0.001$ & & & $<0.001$ \\
\hline Public employee & 267 & (10.54) & 10 & 3.75 & & 25 & 9.36 & \\
\hline Commercial employee & 288 & (11.37) & 12 & 4.17 & & 25 & 8.68 & \\
\hline Peasant & 745 & $(29.40)$ & 118 & 15.84 & & 230 & 30.87 & \\
\hline Others & 1234 & $(48.70)$ & 53 & 4.29 & & 131 & 10.62 & \\
\hline Marital status & & & & & 0.513 & & & 0.292 \\
\hline Unmarried & 52 & $(2.05)$ & 2 & 3.85 & & 6 & 11.54 & \\
\hline Married & 2224 & $(87.77)$ & 172 & 7.73 & & 370 & 16.64 & \\
\hline Others & 258 & (10.18) & 19 & 7.36 & & 35 & 13.57 & \\
\hline Site of cancer & & & & & 0.002 & & & $<0.001$ \\
\hline Lung & 469 & $(18.51)$ & 50 & 10.66 & & 98 & 20.90 & \\
\hline Breast & 637 & (25.14) & 33 & 5.18 & & 84 & 13.19 & \\
\hline Colorectum & 266 & (10.50) & 18 & 6.77 & & 42 & 15.79 & \\
\hline Oesophagus & 86 & (3.39) & 11 & 12.79 & & 25 & 29.07 & \\
\hline Liver & 110 & $(4.34)$ & 8 & 7.27 & & 19 & 17.27 & \\
\hline Stomach & 200 & (7.89) & 24 & 12.00 & & 46 & 23.00 & \\
\hline Others & 766 & (30.23) & 49 & 6.40 & & 97 & 12.66 & \\
\hline Cancer stage & & & & & 0.181 & & & 0.659 \\
\hline 1 & 453 & 17.88 & 26 & 5.74 & & 75 & 16.56 & \\
\hline II & 476 & 18.78 & 34 & 7.14 & & 71 & 14.92 & \\
\hline III & 402 & 15.86 & 29 & 7.21 & & 65 & 16.17 & \\
\hline IV & 295 & 11.64 & 20 & 6.78 & & 42 & 14.24 & \\
\hline Unclear & 908 & 35.83 & 84 & 9.25 & & 158 & 17.40 & \\
\hline Residency & & & & & $<0.001$ & & & $<0.001$ \\
\hline Urban & 1737 & (68.55) & 89 & 5.12 & & 188 & 10.82 & \\
\hline Rural & 797 & (31.45) & 104 & 13.05 & & 223 & 27.98 & \\
\hline Region & & & & & $<0.001$ & & & $<0.001$ \\
\hline Eastern & 370 & (14.60) & 11 & 2.97 & & 28 & 7.57 & \\
\hline Central & 1088 & (42.94) & 108 & 9.93 & & 207 & 19.03 & \\
\hline Western & 1076 & $(42.46)$ & 74 & 6.88 & & 176 & 16.36 & \\
\hline Insurance & & & & & $<0.001$ & & & $<0.001$ \\
\hline BMIUE & 1210 & $(47.75)$ & 37 & 3.06 & & 102 & 8.43 & \\
\hline
\end{tabular}


Table 1 Continued

\begin{tabular}{|c|c|c|c|c|c|c|c|c|}
\hline \multirow[b]{2}{*}{ Characteristics } & \multirow{2}{*}{\multicolumn{2}{|c|}{$\begin{array}{l}\text { Sample size } \\
\text { N (\%) }\end{array}$}} & \multicolumn{3}{|c|}{$\begin{array}{l}\text { Household consumption below } \\
\text { CPL US } \$ 1.2\end{array}$} & \multicolumn{3}{|c|}{$\begin{array}{l}\text { Household consumption below } \\
\text { global poverty line US } \$ 1.9\end{array}$} \\
\hline & & & Number & $\%$ & P value* & Number & $\%$ & P value* \\
\hline BMIUR & 335 & (13.22) & 25 & 7.46 & & 46 & 13.73 & \\
\hline NCMS & 789 & (31.14) & 104 & 13.18 & & 223 & 28.26 & \\
\hline Others & 200 & $(7.89)$ & 27 & 13.50 & & 40 & 20.00 & \\
\hline Household income & & & & & $<0.001$ & & & $<0.001$ \\
\hline Quintile 1 (bottom 20\%) & 508 & (20.05) & 132 & 25.98 & & 241 & 47.44 & \\
\hline Quintile 2 & 507 & (20.01) & 30 & 5.92 & & 80 & 15.78 & \\
\hline Quintile 3 & 506 & (19.97) & 15 & 2.96 & & 47 & 9.29 & \\
\hline Quintile 4 & 505 & (19.93) & 12 & 2.38 & & 27 & 5.35 & \\
\hline Quintile 5 (top 20\%) & 508 & (20.05) & 4 & 0.79 & & 16 & 3.15 & \\
\hline
\end{tabular}

${ }^{*} \chi^{2}$ tests.

BMIUE, Basic Medical Insurance for Urban Employees; BMIUR, Basic Medical Insurance for Urban Residents; CPL, Chinese poverty line; NCMS, New Cooperative Medical Scheme.

between regional zones and urban-rural residency was weak $(<0.21)$ as indicated by the eco-efficiencies of contingency, phi and Cramer's V, although a statistically significant difference in $\chi^{2}$ test (online supplemental table S3). No significant multicollinearity was identified in the multivariate modelling (online supplemental table S4). Reginal differences in post-treatment household impoverishment remained in the sample excluding rural participants (online supplemental table S6).

The median consumption gap accumulated by the impoverished households post cancer treatment reached US\$128 per capita per year underneath the CPL and US\$212 per capita per year underneath the World Bank poverty line (WBPL), respectively. These amounted to a total of US\$31 million (under CPL) and US $\$ 115$ million (under WBPL) needed to avoid household impoverishment induced by cancer treatment. The impoverished households with the lowest quintile of income also accumulated twice or tripled consumption gaps underneath the poverty line in comparison with their wealthiest counterpart (online supplemental table S7).

\section{DISCUSSION}

This study presents new evidence on household impoverishment induced by cancer treatment in China. About $5.79 \%$ of households became impoverished according to the CPL after paying for cancer treatment OOP. This figure would increase to $12.45 \%$ using the WBPL. Such an incidence appears to be low compared with findings of studies conducted in some other developing countries. ${ }^{11}$ The interpretation of the comparative results needs to be cautious. In this study and others undertaken in China, ${ }^{30}$ indirect costs associated with medical services such as transportation, foods and out-of-hospital accommodations were not included in the estimation of costs for cancer treatment. This may have deflated the real financial burden of cancer treatment in China.

The social health insurance programmes have limited effects on preventing household impoverishment induced by cancer treatment. Although patients without a coverage of any of the three social health insurance programmes are more likely to experience post-treatment household impoverishment than those enrolled with BMIUE, significant increases in household impoverishment after cancer treatment occurred in enrollees of all the three insurance programmes. Patients covered by NCMS appear to have the same chance of falling into poverty as those without coverage of any of the social health insurance programmes. This coincides with the urban-rural disparities in China: NCMS is designed for rural residents who usually have lower income compared with their urban counterparts. ${ }^{31}$ Previous studies found that funding available for NCMS enrollees is only about half of that for BMIUE enrollees. ${ }^{32}$ Empirical evidence shows that public financing is effective in protecting the most vulnerable populations from medical-induced poverty. ${ }^{33-35}$ However, this requires well-targeted investments (the so-called precision poverty alleviation). ${ }^{36}$ This study estimates that at least US $\$ 31$ million will be needed annually to alleviate the impoverishment induced by cancer treatment according to the CPL, or US $\$ 115$ million according to the WBPL. Previous studies showed that BMIUE had the highest level of compensation rates and the lowest OOP requirements in comparison with the other two schemes. ${ }^{23} 37$ The average payments from the insurance programmes for hospital-admitted patients were estimated to be around $68 \%$ for BMIUE, $48 \%$ for BMIUR and $44 \%$ for NCMS in $2011 .{ }^{23}$ The eastern region offered a higher level of compensations. In Suzhou, for example, $73 \%, 71 \%$ and $56 \%$ of hospital charges were covered by BMIUE, BMIUR and NCMS, respectively, in 2014. ${ }^{37}$ 


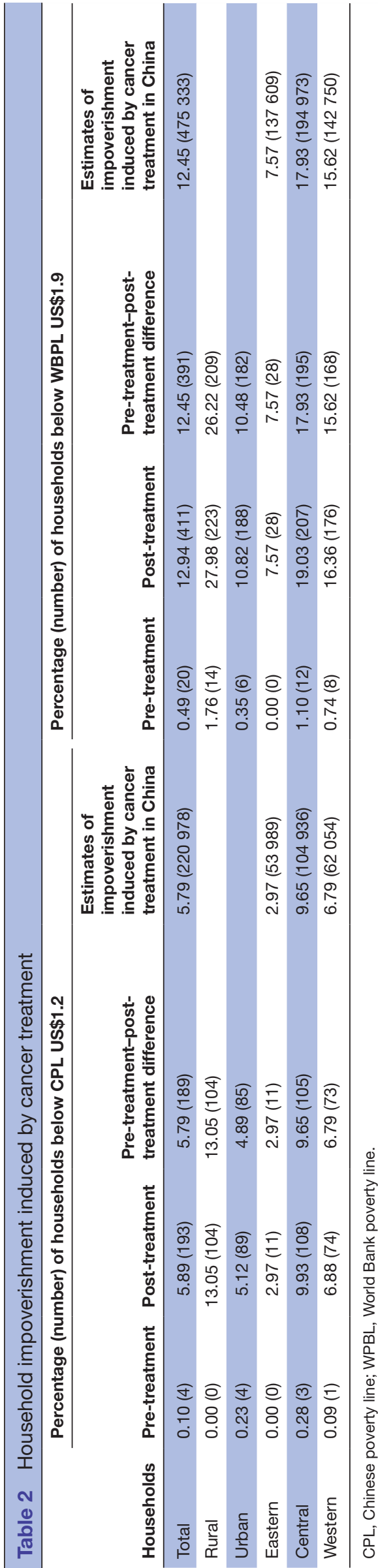

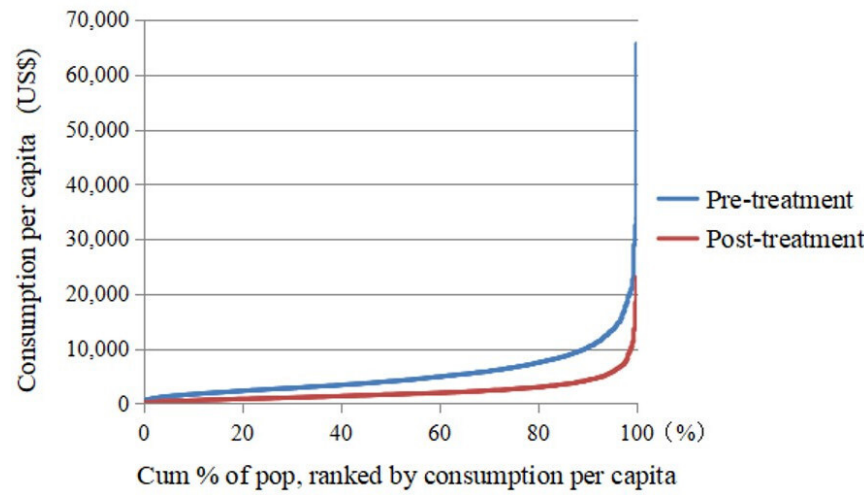

Figure 1 Pen's parade of impoverished households before and after cancer treatment. Horizontal axis: cumulative \% of population, ranked by consumption per capita. Vertical axis: consumption per capita (US\$).

Under-the-table user fees were nominal, if ever existed, due to strict regulations.

Socioeconomic inequality in household impoverishment resulting from cancer treatment in China deserves increasing policy attention. This study found that inequalities exist from a range of perspectives. (1) Households with the lowest quintile of income stand at least four times higher chance of falling into poverty after cancer treatment than the richer ones: more than one quarter of them became impoverished under the CPL or almost $45 \%$ under the global poverty line. These results are consistent with findings of other studies. ${ }^{38-40}$ (2) Rural households have tripled incidence of impoverishment induced by cancer treatment compared with the urban ones. The urban-rural inequality is likely to be a result of income disparities ${ }^{31}$ and disparities in primary care services. ${ }^{41} 42$ The urban-rural difference in incidence of post-treatment household impoverishment disappeared after adjustment for variations in other variables. (3) Like findings of previous studies, ${ }^{11}$ older people were found in this study to suffer more from household impoverishment as a result of cancer treatment. (4) Significant regional disparities exist. Although it is certain that the most developed eastern region is better off, the central developing

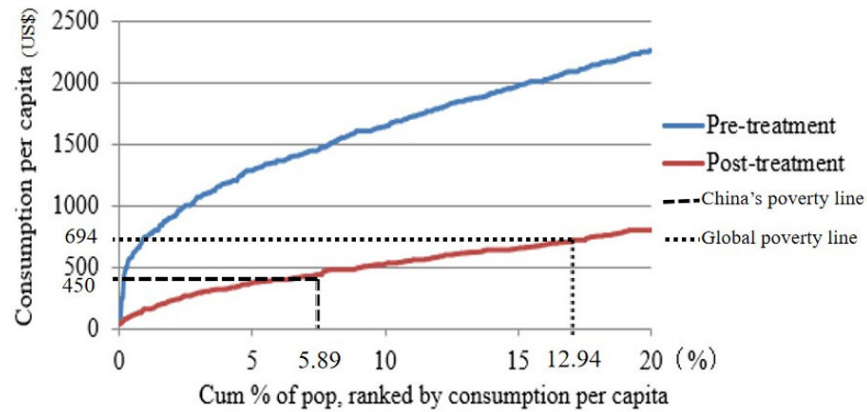

Figure 2 Pen's parade of impoverished households before and after cancer treatment (in view of the bottom 20\%). Horizontal axis: cumulative \% of population, ranked by consumption per capita. Vertical axis: consumption per capita (US\$). 


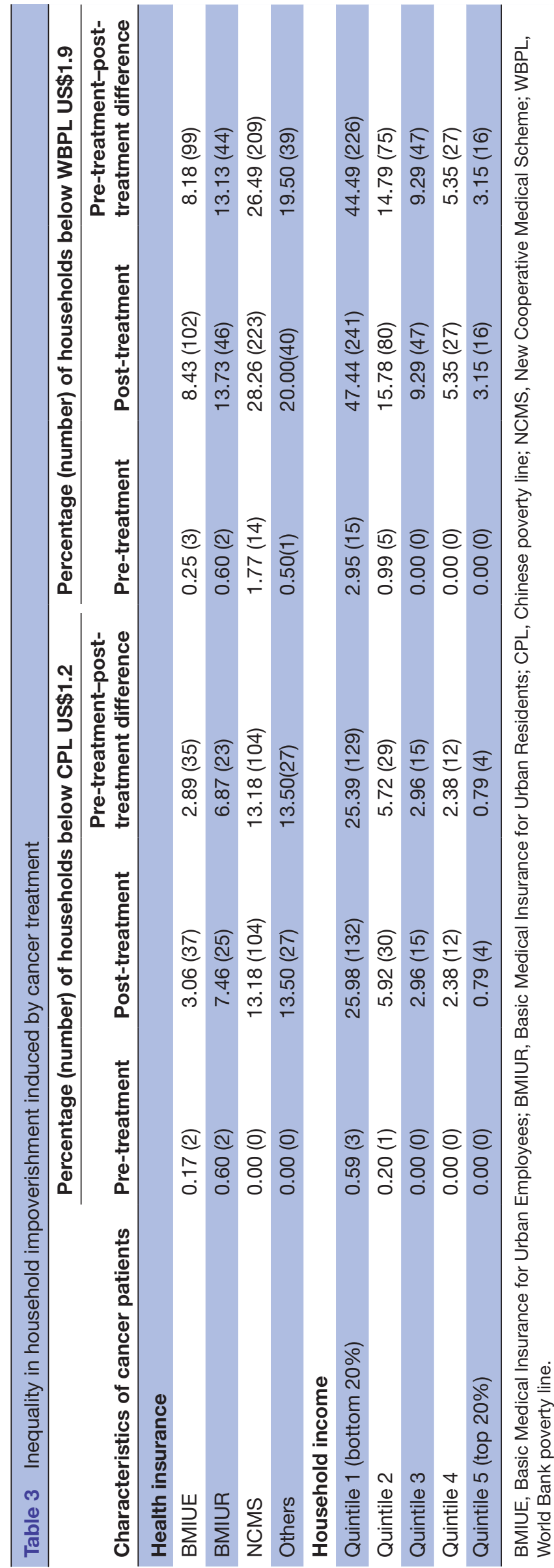

region suffers more than the poorest western region. In 2015, disposable income of the central region averaged at US\$2961 per capita, compared with US\$4531 in the eastern and US\$2708 in the western region. ${ }^{43}$ However, the national government of China has provided significantly more financial subsidies to the western region than to the central region. Previous studies also show that patients from the central region are more likely to seek more expensive medical services compared with their western counterparts due to higher financial capability, convenience of transportation and better accessibility to high medical technologies. ${ }^{44}$

It is important to note that accessibility to healthcare services can be seriously jeopodised by low household income especially in a system that requires high proportions of OOP payments. ${ }^{45}$ This study showed an absence of pre-treatment household impoverishment for rural residents. Empirical evidence shows that some households with low income are likely to forfeit expensive medical care, including cancer treatment to avoid impoverishment. ${ }^{46}$ The actual scale of household impoverishment would be higher should all cancer cases are treated in line with relevant clinical guidelines. Indeed, low household income may suppress the spending of medical care despite wide coverage of health insurance according to the findings of this study.

Findings of this study have some policy implications. The current health insurance programmes in China are highly fragmented, which is, at least partly, a result of the urban-rural dual structure. A better coordinated effort is needed to address the inequality in household impoverishment induced by cancer treatment. This can start from a national central cancer registry system and share of insurance claim data given that the national government of China has been increasing its investments in social health insurance, health services delivery and medical assistance (to help poor households to enrol with social health insurance and pay for OOP expenses) programmes. However, higher insurance entitlements may stimulate consumer demands, increasing the risk of catastrophic health expenditure. Government investments need to be channelled to those most in need. ${ }^{47}$ This may include cross-subsidising mechanisms between urban and rural insurance schemes. Meanwhile, strong cost containment measures need to be taken. The role of primary care in managing cancer patients should be strengthened. Hospital costs should be contained by encouraging evidence-based practices through funding and payment reforms. ${ }^{48}$

This study has several limitations. First, data in this study were collected through questionnaire survey, which are subject to recall bias. The sensitivity test indicates that patient estimation of household consumption is significantly higher than that from the caregivers (online supplemental table S1). Second, the stratified sampling strategy adopted in this study ensured that the minimal sample size could be met in all of the three regions. However, the more populated eastern region was under-represented. 
Table 4 Logistic regression analysis on predictors of the incidence of post-treatment impoverishment in cancer patients

\begin{tabular}{|c|c|c|c|c|}
\hline Characteristics of cancer patients & Crude OR $(95 \% \mathrm{Cl})$ & $P$ value & Adjusted OR $(95 \% \mathrm{Cl})^{\star}$ & $P$ value \\
\hline \multicolumn{5}{|l|}{ Age (years) } \\
\hline$\leq 49$ & 1 (reference) & & 1 (reference) & \\
\hline $50-69$ & 2.544 (1.625 to 3.981$)$ & $<0.001$ & 2.666 (1.659 to 4.285$)$ & $<0.001$ \\
\hline$\geq 70$ & 2.996 (1.805 to 4.974$)$ & $<0.001$ & 4.187 (2.400 to 7.305$)$ & $<0.001$ \\
\hline \multicolumn{5}{|l|}{ Educational attainment } \\
\hline$\leq$ Juniorhigh school & 1 (reference) & & 1 (reference) & \\
\hline Senior high school & 0.463 (0.312 to 0.686$)$ & $<0.001$ & 0.987 (0.637 to 1.530$)$ & 0.955 \\
\hline ZUniversity & $0.192(0.106$ to 0.349$)$ & $<0.001$ & 1.166 (0.572 to 2.376$)$ & 0.673 \\
\hline \multicolumn{5}{|l|}{ Occupation } \\
\hline Public employee & 1 (reference) & & 1 (reference) & \\
\hline Commercial employee & 1.117 (0.475 to 2.631$)$ & 0.799 & 0.731 (0.287 to 1.864$)$ & 0.511 \\
\hline Peasant & 4.837 (2.496 to 9.373$)$ & $<0.001$ & 0.818 (0.341 to 1.964$)$ & 0.653 \\
\hline Others & 1.153 (0.579 to 2.297$)$ & 0.685 & 0.597 (0.271 to 1.316$)$ & 0.201 \\
\hline \multicolumn{5}{|l|}{ Site of cancer } \\
\hline Lung & 1 (reference) & 0.002 & 1 (reference) & \\
\hline Breast & 0.458 (0.290 to 0.723$)$ & 0.001 & 0.538 (0.328 to 0.882$)$ & 0.014 \\
\hline Colorectum & 0.608 (0.347 to 1.066$)$ & 0.082 & 0.624 (0.342 to 1.140$)$ & 0.125 \\
\hline Oesophagus & 1.229 (0.612 to 2.469$)$ & 0.562 & 0.703 (0.328 to 1.504$)$ & 0.363 \\
\hline Liver & 0.657 (0.302 to 1.430$)$ & 0.290 & 0.830 (0.362 to 1.903$)$ & 0.660 \\
\hline Stomach & 1.143 (0.681 to 1.917$)$ & 0.613 & 0.818 (0.463 to 1.444$)$ & 0.488 \\
\hline Others & 0.573 (0.379 to 0.865$)$ & 0.008 & 0.513 (0.324 to 0.814$)$ & 0.005 \\
\hline \multicolumn{5}{|l|}{ Residency } \\
\hline Urban & 1 (reference) & & 1 (reference) & \\
\hline Rural & 2.779 (2.066 to 3.738$)$ & $<0.001$ & 0.993 (0.692 to 1.425$)$ & 0.970 \\
\hline \multicolumn{5}{|l|}{ Region } \\
\hline Eastern & 1 (reference) & & 1 (reference) & \\
\hline Central & 3.597 (1.912 to 6.767$)$ & $<0.001$ & 2.619 (1.317 to 5.206$)$ & 0.006 \\
\hline Western & 2.410 (1.265 to 4.593$)$ & 0.007 & 1.535 (0.766 to 3.076$)$ & 0.227 \\
\hline \multicolumn{5}{|l|}{ Health insurance } \\
\hline BMIUE & 1 (reference) & & 1 (reference) & \\
\hline BMIUR & 2.557 (1.516 to 4.312 ) & $<0.001$ & 1.225 (0.683 to 2.195$)$ & 0.496 \\
\hline NCMS & 4.813 (3.269 to 7.087 ) & $<0.001$ & 1.355 (0.827 to 2.219$)$ & 0.228 \\
\hline Others & 4.948 (2.938 to 8.332$)$ & $<0.001$ & 1.880 (1.030 to 3.431$)$ & 0.040 \\
\hline \multicolumn{5}{|l|}{ Household income } \\
\hline Quintile 1 (bottom 20\%) & 1 (reference) & & 1 (reference) & \\
\hline Quintile 2 & 0.179 (0.118 to 0.272$)$ & $<0.001$ & 0.187 (0.121 to 0.288$)$ & $<0.001$ \\
\hline Quintile 3 & 0.087 (0.050 to 0.151$)$ & $<0.001$ & 0.094 (0.052 to 0.171$)$ & $<0.001$ \\
\hline Quintile 4 & 0.069 (0.038 to 0.127$)$ & $<0.001$ & 0.072 (0.037 to 0.142 ) & $<0.001$ \\
\hline Quintile 5 (top 20\%) & 0.023 (0.008 to 0.062$)$ & $<0.001$ & 0.024 (0.008 to 0.070$)$ & $<0.001$ \\
\hline
\end{tabular}

${ }^{*} R^{2}$ of Cox and Snell $=0.104 ; R^{2}$ of Nagelkerke $=0.249 ; R^{2}$ of McFadden $=0.203$.

BMIUE, Basic Medical Insurance for Urban Employees; BMIUR, Basic Medical Insurance for Urban Residents; NCMS, New Cooperative Medical Scheme.

Third, non-medical costs like travel were excluded in this study. The financial sources of household consumption were unknown. Some households were likely to borrow money to pay for the consumptions. Household impoverishment was determined by daily consumption in this study, which is a widely accepted approach. However, we 
did not examine the source of income for household consumptions. If some households borrowed money or realised assets to pay for daily consumption, this could lead to potential underestimation of household impoverishment. Further studies are needed to examine whether income falls post treatment (people losing their jobs), which categories of consumption are most impacted by cancer treatment spending, and where households are deciding to cut costs.

\section{CONCLUSION}

The financial burden of cancer treatment imposes a significant risk of household impoverishment in China despite an almost universal coverage of social health insurance. The risk falls disproportionally onto the households living with low income. Significant socioeconomic inequalities exist in household impoverishment resulting from cancer treatment. Unbalanced regional development and fragmentation of health insurance programmes may have jeopardised the efforts in alleviating poverty induced by medical services.

\section{Author affiliations}

${ }^{1}$ Department of Health Economics, School of Health Management/Public Health, Harbin Medical University, Harbin, China

${ }^{2}$ Office of Cancer Screening, National Cancer Center/National Clinical Research Center for Cancer/Cancer Hospital, Chinese Academy of Medical Sciences and Peking Union Medical College, Beijing, China

${ }^{3}$ Department of Public Health, School of Psychology and Public Health, La Trobe University, Bundoora, Victoria, Australia

${ }^{4}$ Department for Prevention and Control of Chronic Non-communicable Diseases, Harbin Center for Disease Control and Prevention, Harbin, China

${ }^{5}$ Department of Medical Administration, Yunnan Provincial Cancer Hospital, Kunming, China

${ }^{6}$ Department of Preventive Medicine, School of Public Health, Guangxi Medical University, Nanning, China

${ }^{7}$ Department of Hematology and Oncology, Affiliated Hospital of Inner Mongolia University for Nationalities, Tongliao, China

${ }^{8}$ Department of Cancer Prevention, Sun Yat-sen University Cancer Center, Guangzhou, China

${ }^{9}$ Department of Epidemiology, Shanxi Provincial Cancer Hospital, Taiyuan, China

${ }^{10}$ Health Management College, Anhui Medical University, Hefei, China

Acknowledgements The authors appreciate support from the National Cancer centre of China, the seven participating provinces, the Health Economic Evaluation Working Group and the Cancer Screening Programme in Urban China. We thank all of the study participants.

Contributors GL, JS, WF, XZ, Chengcheng Liu, LL, MZ, LY, BB, SC, YZ, DW, NL, WC, $\mathrm{MD}$ and $\mathrm{JH}$ designed the study, implemented the survey and collected data. GL, Chaojie Liu, WF, CS, YD and HW analysed the data. WF and Chaojie Liu prepared the manuscript. All the authors read and approved the final version of the manuscript.

Funding This work was supported by National Key R\&D Program of China (grant numbers: 2017YFC1308700 and 2017YFC1308705); National Natural Science Foundation of China (grant numbers: 71603065 and 71673071) and the National Key Public Health Programme of China (Cancer Screening Programme in Urban China) (grant number: N/A).

Competing interests None declared.

Patient consent for publication Not required.

Ethics approval The study protocol was approved by the institutional review board of the Cancer Hospital of Chinese Academy of Medical Sciences (approval number: 15-071/998)

Provenance and peer review Not commissioned; externally peer reviewed.
Data availability statement No data are available.

Supplemental material This content has been supplied by the author(s). It has not been vetted by BMJ Publishing Group Limited (BMJ) and may not have been peer-reviewed. Any opinions or recommendations discussed are solely those of the author(s) and are not endorsed by BMJ. BMJ disclaims all liability and responsibility arising from any reliance placed on the content. Where the content includes any translated material, BMJ does not warrant the accuracy and reliability of the translations (including but not limited to local regulations, clinical guidelines, terminology, drug names and drug dosages), and is not responsible for any error and/or omissions arising from translation and adaptation or otherwise.

Open access This is an open access article distributed in accordance with the Creative Commons Attribution Non Commercial (CC BY-NC 4.0) license, which permits others to distribute, remix, adapt, build upon this work non-commercially, and license their derivative works on different terms, provided the original work is properly cited, appropriate credit is given, any changes made indicated, and the use is non-commercial. See: http://creativecommons.org/licenses/by-nc/4.0/.

\section{ORCID iDs}

Wenqi Fu http://orcid.org/0000-0002-4847-9191

Chaojie Liu http://orcid.org/0000-0003-0877-0424

Guoxiang Liu http://orcid.org/0000-0002-4839-4307

\section{REFERENCES}

1 Bevans M, Sternberg EM. Caregiving burden, stress, and health effects among family caregivers of adult cancer patients. JAMA 2012;307:398-403.

2 Ferlay J, Soerjomataram I, Dikshit R, et al. Cancer incidence and mortality worldwide: sources, methods and major patterns in GLOBOCAN 2012. Int J Cancer 2015;136:E359-86.

3 Bray F, Ferlay J, Soerjomataram I, et al. Global cancer statistics 2018: GLOBOCAN estimates of incidence and mortality worldwide for 36 cancers in 185 countries. CA Cancer J Clin 2018;68:394-424.

4 Wild CP, S B. World cancer report 2014. Lyon: International Agency for Research on Cancer, 2014.

5 Chen W, Zheng R, Baade PD, et al. Cancer statistics in China, 2015. CA Cancer J Clin 2016;66:115-32.

6 China NBoSo. China statistical yearbook, 2018. Beijing: China Statistics Press, 2018.

7 Rotter JS, Spencer JC, Wheeler SB. Can cancer care costs impact quality of life outcomes for the entire household? Psychooncology 2019;28:924-7.

8 Leopold C, Wagner AK, Zhang F, et al. Total and out-of-pocket expenditures among women with metastatic breast cancer in lowdeductible versus high-deductible health plans. Breast Cancer Res Treat 2018;171:449-59.

9 Huang $\mathrm{H}-\mathrm{Y}$, Shi J-F, Guo L-W, et al. Expenditure and financial burden for common cancers in China: a hospital-based multicentre crosssectional study. The Lancet 2016;388:S10.

10 Azzani M, Roslani AC, Su TT. Determinants of household catastrophic health expenditure: a systematic review. Malays J Med Sci 2019;26:15-43

11 Hoang VM, Pham CP, Vu QM, et al. Household financial burden and poverty impacts of cancer treatment in Vietnam. Biomed Res Int 2017;2017:9350147

12 Organization WH. The world health report 2000 health systems: improving performance, 2000: 2-44.

13 Liu B, Lao X, Feng Y, et al. Cancer prevalence among the rural poverty-stricken population in northeast China. Cancer Manag Res 2019;11:5101-12.

14 Rossell N, Challinor J, Gigengack R, et al. Choosing a miracle: Impoverishment, mistrust, and discordant views in abandonment of treatment of children with cancer in El Salvador. Psychooncology 2017;26:1324-9.

15 Kollman J, Sobotka HL. Poverty and cancer disparities in Ohio. Prev Chronic Dis 2018;15:E152.

16 Kehl KL, Lathan CS, Johnson BE, et al. Race, poverty, and initial implementation of precision medicine for lung cancer. J Natl Cancer Inst 2019;111:431-4.

17 Williams F, Thompson E. Disparities in breast cancer stage at diagnosis: importance of race, poverty, and age. $J$ Health Dispar Res Pract 2017:10:34-45.

18 Mader L, Roser K, Baenziger J, et al. Household income and risk-ofpoverty of parents of long-term childhood cancer survivors. Pediatr Blood Cancer 2017;64. doi:10.1002/pbc.26456. [Epub ahead of print 06 Mar 2017]. 
19 Hosseinpoor AR, Bergen N, Schlotheuber A, et al. National health inequality monitoring: current challenges and opportunities. Glob Health Action 2018;11:1392216

20 Sun J, Lyu S. The effect of medical insurance on catastrophic health expenditure: evidence from China. Cost Eff Resour Alloc 2020;18:11.

21 Shu Z, Han Y, Xiao J, Zhan Shu YH, Li J, et al. Effect of medical insurance and family financial risk on healthcare utilisation by patients with chronic diseases in China: a cross-sectional study. BMJ Open 2019;9:e030799.

22 Wang Q, Shen J, Rice J, et al. Social health insurance difference in inpatient expenditure and service category in China. Asia Pac J Public Health 2018;30:56-66.

23 Zhao C, Wang C, Shen C, et al. China's achievements and challenges in improving health insurance coverage. Drug Discov Ther 2018;12:1-6.

24 Chen C, Pan J. The effect of the health poverty alleviation project on financial risk protection for rural residents: evidence from Chishui City, China. Int J Equity Health 2019;18:79.

25 Dai M, Shi J, Li N. The design and expectation of the cancer screening program in urban China. Zhonghua Yu Fang Yi Xue Za Zhi 2013;47:179-82.

26 Hongbing Shen XQ. Epidemiology. 8 edn. Beijing: People's medical publishing house, 2013.

27 Wagstaff A, van Doorslaer E. Catastrophe and impoverishment in paying for health care: with applications to Vietnam 1993-1998. Health Econ 2003;12:921-33.

28 Anonymous. Ending extreme poverty and sharing prosperity: progress and policies. Global Monitoring Report, 2015: 27-86.

29 Haughton J, Khandker SR. Handbook on poverty and inequality. Washington, DC: World Bank, 2009.

30 Zhang X, Liu S, Liu Y, et al. Economic burden for lung cancer survivors in urban China. Int J Environ Res Public Health 2017;14. doi:10.3390/ijerph14030308. [Epub ahead of print: 15 Mar 2017].

31 China NBoSo. China health statistics yearbook 2016. Beijing, China: China statistics press, 2016

32 Hdr center. China National health accounts report. Beijing, China: Health development research center, 2016.

33 Rajan D, Barroy H, S K. Budgeting for health. In: Schmets G, Rajan D, Kadandale S, eds. Strategizing National health in the 21st century: a handbook. Geneva: World Health Organisation, 2016.

34 Barroy HML, Hsu J, Van de MN. Public financing for health in Africa: from Abuja to the SDGs. Geneva: World Health Organisation, 2016.
35 Goryakin Y, Revill P, Mirelman A. Public financial management and health service delivery: a literature review. London, UK: Overseas Development Institute, 2017.

36 Ross J. Improved reproductive health equity between the poor and the rich: an analysis of trends in 46 low- and middle-income countries. Glob Health Sci Pract 2015;3:419-45.

37 Li Y, Zhao Y, Yi D, et al. Differences exist across insurance schemes in China post-consolidation. PLoS One 2017;12:e0187100.

38 Yardim MS, Cilingiroglu N, Yardim N. Catastrophic health expenditure and impoverishment in turkey. Health Policy 2010;94:26-33.

39 Su TT, Kouyaté B, Flessa S. Catastrophic household expenditure for health care in a low-income Society: a study from Nouna district, Burkina Faso. Bull World Health Organ 2006;84:21-7.

40 Azzani M, Yahya A, Roslani AC, et al. Catastrophic health expenditure among colorectal cancer patients and families: a case of Malaysia. Asia Pac J Public Health 2017;29:485-94.

$41 \mathrm{Li} \mathrm{Y,} \mathrm{Sun} \mathrm{Y,} \mathrm{Zhang} \mathrm{Y,} \mathrm{et} \mathrm{al.} \mathrm{Rural-urban} \mathrm{disparity} \mathrm{in} \mathrm{health} \mathrm{care:}$ observations from Suzhou, China. Public Health 2016;138:164-7.

42 Liu X, Li N, Liu C, et al. Urban-rural disparity in utilization of preventive care services in China. Medicine 2016;95:e4783.

43 China NBoSo. China statistics yearbook. Beijing, China: China statistics press, 2016.

44 Sun J, Luo H. Evaluation on equality and efficiency of health resources allocation and health services utilization in China. Int $J$ Equity Health 2017;16:127.

45 Adugna MB, Nabbouh F, Shehata S, et al. Barriers and facilitators to healthcare access for children with disabilities in low and middle income sub-Saharan African countries: a scoping review. BMC Health Serv Res 2020;20:15.

46 Murphy A, Palafox B, Walli-Attaei M, et al. The household economic burden of non-communicable diseases in 18 countries. BMJ Glob Health 2020;5:e002040.

47 Ogbuabor DC, Onwujekwe OE. Aligning public financial management system and free healthcare policies: lessons from a free maternal and child healthcare programme in Nigeria. Health Econ Rev 2019:9:17.

48 Bergström A, Skeen S, Duc DM, et al. Health system context and implementation of evidence-based practices-development and validation of the context assessment for community health (coach) tool for low- and middle-income settings. Implement Sci 2015;10:120. 